\title{
Análise do uso de formalização de conhecimento heurístico no ensino de táticas de jogos através do estímulo à alternância entre competição e colaboração
}

Assessing the use and formalization of heuristic knowledge in the teaching of game tactics by encouraging switching between competition and collaboration

Alexandre Feitosa

COADS - Campus Cornélio Procópio

UTFPR - Universidade Tecnológica Federal do Paraná

alexandrefeitosa@utfpr.edu.br
Alexandre Direne

Departamento de Informática

UFPR - Universidade Federal do Paraná

alexd@inf.ufpr.br

\begin{abstract}
Resumo Nesta pesquisa verificamos a hipótese de que o estímulo à formalização de conhecimento heuristico de jogo por aprendizes contribui para que estes compreendam melhor, os conceitos trabalhados durante a aprendizagem. Atividade feita em uma ferramenta computacional de ensino onde o educando formaliza o seu conhecimento heurístico de jogo. E esta representação criada pode ser estudada, discutida, e validada através de jogadores automáticos, quando ela é utilizada como lógica de escolha de jogadas em uma partida automatizada. Um processo que permite a alternância entre a colaboração e competição entre os alunos. Até o presente estudo a eficácia desta abordagem não podia ser atestada. Com o intuito de realizar esta aferição, revisamos na literatura trabalhos relacionados a este tema. Expandimos os conceitos e softwares, para permitir a competição artificial entre as especificações feitas. Conduzimos um estudo empírico sobre o uso deste novo ferramental, em um ambiente real de ensino e aprendizagem de xadrez. E a partir da análise dos resultados encontrados, constatamos que a proposição inicial demonstrou-se verdadeira.
\end{abstract}

Palavras-Chave: Inteligência Artificial; Formalização de Heurísticas; Jogadores automáticos; Jogo de xadrez; Apoio computacional ao ensino; Alternância entre competição e colaboração.

\begin{abstract}
This research explores the hypothesis that stimulating the formalization of learners' heuristic knowledge of game tactics helps their better understanding of the concepts used during learning. Activities are carried out in a software tool that supports classical chess teaching by formalizing the heuristic knowledge of the game. Knowledge created with the tool can be studied, discussed, and validated through artificial matchings. An additional process allows switching between collaboration and competition among the students. In order to assess the effectiveness of the method and tools, we reviewed the related literature on this subject of competitions among the artificially made specified game tactics. We then conducted an empirical study on the use of this new tooling in a real environment for teaching and learning chess. From the analysis, we found that the initial proposition was found to be valid.
\end{abstract}

Keywords: Artificial Intelligence; Heuristic formalization; Artificial matching; Game of chess; Computer-supported Learning; Switching between competition and collaboration. 


\section{Introdução}

Nos tipos de jogos estocásticos (algumas vezes chamados de "jogos de azar"), o uso de fatores de aleatoriedade (e.g., sorteio, uso de dados) faz parte da regra dos mesmos. E neste caso, o jogador depende em certa medida de sorte para alcançar a vitória.

Já os jogos que não possuem aleatoriedade são chamados de heurísticos, como o xadrez e damas. Nestes a vitória depende exclusivamente da habilidade estratégica do jogador, e não é suficiente escolher um movimento de forma isolada, se faz necessário à adoção de planos que incluam mais de um lance. Com o intuito de obter pequenas vantagens, que contribuam para o objetivo maior que é a vitória (Ver seção 2.1).

No xadrez as vantagens que acontecem em uma partida são categorizadas em [1]:

- Material (força): Refere-se às características de uso das peças que o jogador possui. Ou seja, as possibilidades de ataque e de defesa que elas proporcionam.

- Espacial (posicional): Está relacionada à ocupação territorial do tabuleiro. Possuir peças em determinadas regiões pode ser considerado uma vantagem de acordo com a situação, e o momento.

- Temporal (de desenvolvimento): É importante que se use a vez de jogar para construir vantagens, e não a desperdice. Então esta vantagem refere-se ao tempo usado ou que resta a um jogador para conseguir uma meta, e pode ser em total de lances.

O enxadrista deve analisar a situação atual da partida, e identificar as características que se configuram em vantagens e desvantagens a ele e ao oponente. E a partir desta crítica, escolher qual plano adotar para alcançar determinada objetivo (Ver seção 2.1).

Jogar xadrez bem é uma atividade complexa, e a perícia só é alcançada após muito estudo e treino. $\mathrm{O}$ ensino dele normalmente é feito através da alternância entre estas etapas: (i) o instrutor apresenta os elementos do jogo, as regras de transformação das peças, explica as principais táticas e estratégias, e direciona o aprendiz a um estudo contextualizado de casos reais e hipotéticos; (ii) o estudante é estimulado a fixar os conhecimentos teóricos aprendidos, e aperfeiçoá-los através da competição contra outros jogadores, que podem ser humanos ou artificiais.

O primeiro problema deste método é que o aluno não é estimulado a formalizar quais conhecimentos teóricos, e quais vantagens ele está considerando durante a escolha de suas jogadas. Outro agravante, é que as técnicas de jogo não são especificadas detalhadamente, o que dificulta a identificação de qual foi adotado em determinada situação. Por exemplo, existe a tática onde se busca " $d o$ minar o centro" do tabuleiro durante um período da partida, a Figura 1 exibe um caso em que especialistas identificam que as pretas estão utilizando desta técnica.

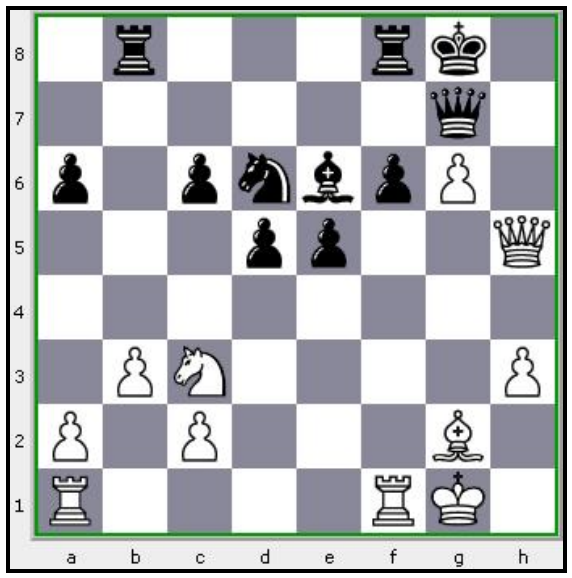

Figura 1 - Exemplo de domínio de centro pelas pretas [3].

O reconhecimento do uso da tática na Figura 1 é subjetivo, visto que a definição do que é o "centro", e quando uma região está "dominada", depende da interpretação de cada enxadrista. Para alguns o "centro" pode ser as 4 casas centrais do tabuleiro $(d 4, e 4, d 5$, e $e 5)$, para outros são as 12 células centrais $(c 4, d 4, e 4, f 4, c 5, d 5, e 5, f 5, c 6$, $d 6$, e6, e $f 6$ ). E dominar uma área pode significar ter mais peças que o adversário naquelas posições, ou ter mais peças que ataquem esta região, mesmo fora dela.

Outro problema deste modo de ensino, é que a perícia na percepção dos conceitos utilizados só é alcançada após uma análise exaustiva de várias situações, e o uso correto destas táticas e estratégias só se fixa após a participação em muitas competições. Pois à validação da aprendizagem feita através de competição é imprecisa, decorrente de que mesmo para um instrutor experiente, é complexo identificar exatamente quais foram os planos e parâmetros adotados pelo aluno durante um jogo. Assim as correções de postura passadas ao estudante ficam incompletas. A precisão da ação do professor poderá só vir através da análise de várias ocorrências do mesmo comportamento, sendo executado pelo mesmo aprendiz.

Esta abordagem didático-pedagógica não propícia ao indivíduo o entendimento do conceito de heurística, e não o estimula a formalizar detalhadamente as suas decisões adotadas durante as partidas. Isto se deve em grande parte, pela inexistência de linguagens e ferramentas que permitam descrever formalmente conhecimentos heurísticos de jogo, de forma fácil e sistemática. 
A escassez de estudos nesta área decorre da dificuldade em criar formas fáceis de representação, e de manipulação deste tipo de conhecimento por leigos, que é o caso dos enxadristas iniciantes que não possuem domínio prévio de conceitos e técnicas de Inteligência Artificial.

Um passo importante em direção a este objetivo foi feito pelo projeto PROTEX, de apoio computacional ao ensino de xadrez, que propôs um ambiente onde o aprendiz formaliza o seu conhecimento heurístico de jogo, e esta representação criada pode ser estudada, discutida, e compartilhada com outros aprendizes. E através de jogadores automáticos a heurística definida por um indivíduo pode ser validada, quando esta é usada como método de escolha de lances em uma partida artificial [2].
Alguns conceitos e ferramentas de software para este ambiente já foram descritos em [1], onde é apresentada a Linguagem para Definição de Heurísticas de Jogo DHJOG, e a ferramenta de autoria de conhecimento heurístico de xadrez HeuChess. A Tabela 1 traz como exemplo, uma possível formalização da tática de domínio de centro através desta linguagem.

Estas primeiras soluções já atenderam alguns prérequisitos para o uso da formalização de heurísticas no ensino de xadrez. Mas até este trabalho elas haviam sido validadas apenas de forma conceitual, através da análise teórica feita por especialistas, pois dependiam de aprimoramentos para que pudessem ser disponibilizadas de forma funcional para aprendizes e instrutores.

\begin{tabular}{|c|c|}
\hline $\begin{array}{l}\text { Linguagem } \\
\text { Natural }\end{array}$ & $\begin{array}{l}\text { Caso a quantidade de peças minhas no centro do tabuleiro seja maior que a quantidade } \\
\text { de peças no centro do oponente, esta situação vale } 20 \% \text { a mais do que o normal. }\end{array}$ \\
\hline & CASA [ ] "CENTRO" <- $<\mathrm{c} 6, \mathrm{~d} 6, \mathrm{e} 6, \mathrm{f} 6, \mathrm{c} 5, \mathrm{~d} 5, \mathrm{e} 5, \mathrm{f5}, \mathrm{c} 4, \mathrm{~d} 4, \mathrm{e} 4, \mathrm{f} 4, \mathrm{c} 3, \mathrm{~d} 3, \mathrm{e} 3, \mathrm{f} 3\}$ \\
\hline DHJOG & $\begin{array}{l}\text { HEURISTICA VALOR_TABULEIRO "DOMINIO_DE_CENTRO" } \\
\text { SE } \\
\text { QUANTIDADE_PECAS ( }\{\text { PEAO, TORRE,CAVALO,BISPO,DAMA,REI }\}, \text { CENTRO,EU) > } \\
\text { QUANTIDADE_PECAS ( }\{\text { PEAO, TORRE,CAVALO,BISPO,DAMA,REI }\}, \text { CENTRO, OPONENTE) } \\
\text { ENTAO } \\
\quad \text { TABULEIRO <- TABULEIRO } \times 1,2 \\
\text { FIM HEURISTICA }\end{array}$ \\
\hline
\end{tabular}

Tabela 1 - Exemplo de formalização de heurística de domínio de centro na DHJOG.

A hipótese que propomos nesta pesquisa é a de que o estimulo a formalização de conhecimento heurístico de jogo por aprendizes, e da colaboração e competição artificial entres eles, contribui para uma melhor compreensão dos conceitos trabalhados de jogo.

Com o intuito de aferir esta proposição, elencamos metas que foram concretizadas durante esta pesquisa, são elas: (i) expansão das funcionalidades do sistema de formalização heurística; (ii) avaliação empírica sobre o uso deste ferramental em um processo de ensino e aprendizagem; (iii) diagnóstico dos problemas e benefícios encontradas na utilização; e (iv) proposição de novos estudos para melhoria dos conceitos e ferramentas de software.

\section{Resenha literária}

Foi realizada uma revisão bibliográfica dos trabalhos relacionados a este tema, com o intuito de levantar questões que contribuíssem com a identificação do problema, das limitações, e que auxiliassem na proposição de novas soluções. Descreveremos as principais análises feitas.

\subsection{Processos cognitivos dos enxadristas}

Existem estudos associados à descoberta das características que contribuem para a eficácia no xadrez. A compreensão destes aspectos, e de que forma estes estão relacionados, permiti uma melhor visão de como a formaliza- ção do conhecimento heurístico pode contribuir para o desenvolvimento de algumas destas habilidades.

Cleveland em [3] identificou que o aperfeiçoamento da capacidade de avaliação é fundamental para que o aprendiz chegue ao estágio de formular planos e desenvolver o seu jogo. Neste processo a manipulação de unidades complexas é essencial para que o jogador evolua.

Já De Groot em [4] elencou as fases do planejamento enxadrístico, são elas: (i) orientação; (ii) exploração; (iii) investigação; e (iv) prova. E os fatores que levam a habilidade no jogo, os principais são: capacidade de analisar hipóteses; formar uma memória especializada; e planejar as jogadas (i.e., criar, adaptar, e encadear planos).

$\mathrm{Na}$ tarefa de planejar os próximos lances, o jogador deve também prever os do adversário, e assim escolher o caminho que lhe garanta a maior vantagem, e a maior desvantagem ao oponente. $\mathrm{O}$ algoritmo minimax baseiase nesta lógica comportamental [5].

Pesquisas sobre a memória concluem que: a diferença entre um iniciante e um especialista, é a quantidade de situações de partida que ele conseguiu adquirir (e que pode reutilizar) nos anos de experiência de jogo; e que o armazenamento destes modelos é feito de forma especializada, associando características visuais com situações de tabuleiro, e usando estes padrões para comparar e classificar os casos estudados [6]. 
A forma como o cérebro de um especialista em xadrez lida com esta tarefa é mais eficaz do que a de um novato. E esta perícia é uma habilidade adquirida e não natural, e não existem atalhos para ela, deve ser desenvolvida através de um processo continuo de aprendizagem [7].

A maioria dos experimentos para a identificação destas competências foi centrada nos jogadores especialistas, e as poucas que incluíram iniciantes não acompanharam a evolução dos mesmos. Ou seja, existe uma lacuna de estudos que ajudem a compreender como as aptidões evoluem no indivíduo, e apontem quais são mais importantes em cada fase de aprendizagem.

\subsection{Evolução dos competidores automáticos de xadrez}

Desde o início da computação moderna, a criação de um programa capaz de vencer um grande enxadrista humano foi uma meta a ser alcançada. Fato que só ocorreu em 1997 [8]. Neste período importantes questões de xadrez vieram à tona, e muitas técnicas de Inteligência Artificial surgiram para atender esta demanda.

As primeiras soluções buscavam ganhar apenas pela força bruta, através do aumento da profundidade de busca, porém isto se mostrou ineficiente, pois foi identificada a tendência Diminishing returns, onde conforme cresce a profundidade da busca pela solução, diminui exponencialmente a chance de se encontrar boas jogadas. Foi compreendido então que se fazia necessário integrar mais conhecimento de xadrez no processo de escolha de movimentos. E que investir no uso de melhor conhecimento trás uma eficiência maior do que investir na mesma razão no aprofundamento da busca [9].

Com a enorme quantidade de possibilidades existentes no xadrez, não é possível criar uma árvore de análise com todas as possíveis jogadas à frente. Diversas técnicas amenizam esta situação, as principais são: (i) minimax com poda Alfa-Beta $(\alpha-\beta)$; (ii) uso de tabelas de transposição; (iii) aprofundamento iterativo da busca; e (iv) uso de movimentos de livros (base de casos) [10].

A vitória da máquina ocorreu quando o campeão internacional de xadrez Kasparov foi derrotado pelo Deep Blue II, da IBM. Este supercomputador analisava até 330 milhões de posições por segundo, onde para a escolha de cada jogada pesquisava 30 bilhões de movimentos. Trabalhava com uma profundidade de pesquisa de 14 lances, podendo chegar até 40 . Utilizava uma base com 4.000 posições de abertura, 700.000 partidas de grandes mestres, e finais de jogo resolvidos com todas as jogadas possíveis com 5, e muitas com até 6 peças [8].

O homem foi derrotado pela capacidade de processamento do computador, através da mineração de padrões de jogo dentro de gigantescas bases de partidas, aberturas, e finais. Isto faz com que os jogadores automáticos de xadrez aparentem ter mais inteligência do que realmente possuem sobre a teoria do jogo.

Atualmente os jogadores automáticos tornaram-se exímios adversários, e são utilizados na prática e treino do xadrez. Contudo estão longe de serem treinadores, visto que existe uma grande separação entre as técnicas adotadas na construção destes, e as usadas na criação de softwares educacionais inteligentes.

\subsection{Aprendizagem individual apoiada por software}

Jogadores automáticos são os programas mais usados para o ensino e aprendizagem do jogo. Utilizados principalmente para o aperfeiçoamento através da competição. Os principais possuem módulos educativos, contudo não fornecem o acompanhamento e adaptação necessária do conteúdo ao aprendiz. Não sendo eficazes para um primeiro contato com o jogo. Sendo assim, os instrutores de xadrez normalmente não usam estes softwares para a exposição de conteúdos, apenas para a prática e fixação.

Existem outros programas de xadrez, a maioria comerciais, com foco estritamente educacional. Entretanto estes apenas são apresentadores de conteúdos específicos. Onde é feita uma prévia explanação, e depois se verifica a aprendizagem através da resolução de exercícios, ou na competição contra jogadores artificiais [11]. Da mesma forma que os primeiros softwares instrucionais CAI (Computer-Assisted Instruction), a maioria não faz nenhuma detecção do perfil do aluno, e quando a faz, esta é feita de forma incompleta.

Os aprendizes possuem particularidades (e.g., cognitivas, comportamentais, etc.) que devem ser consideradas durante a definição da estratégia de ensino. Por isto, foram criados os Sistemas Tutoriais Inteligentes (STI), que buscam agregar técnicas de Inteligência Artificial para que o processo educacional se adapte às características de cada aprendiz, a cada etapa da aprendizagem [12].

Um dos primeiros STIs para xadrez foi o sistema UMRAO, de ensino de finalizações do tipo Bispo-peão [13]. Na sequência foi proposto o ICONCHESS, para ensino de táticas de meio de jogo. Este se apoiou em fatores levantados pela psicologia cognitiva neste domínio, como a importância do reconhecimento de padrões inexatos [4], e do uso de conhecimento de alto nível [14].

Como visto na seção 2.1, um enxadrista especialista é perito no reconhecimento de padrões visuais do xadrez. Lesgold em [6] relacionou as semelhanças entre o desenvolvimento da habilidade de um radiologista em analisar uma imagem clínica, com a de um enxadrista se 
aperfeiçoando em interpretar uma posição de partida. E a partir desta constatação, foi proposto em [15] o ambiente SAEX, que apoia o aprimoramento da capacidade do aprendiz em classificar imagens, identificando características e anomalias de jogo [15].

Após o SAEX, Direne et al. propuseram em [2] o PROTEX (Projeto de Tipificação do Ensino de Xadrez), que fomenta o desenvolvimento de ferramentas computacionais para apoio ao ensino de xadrez. Esta iniciativa foi criada em parceria com o CEX (Centro de Excelência de Xadrez, www.cex.org.br). E a pesquisa descrita neste artigo está inserida neste projeto.

Apesar de estes sistemas inteligentes contribuírem com novas abordagens de ensino de algumas perícias do jogo, estes não incorporaram mecanismos de acompanhamento, nem de adaptação do processo de aprendizagem. E nenhuma solução foi encontrada em que se permite ao aprendiz formalizar seu conhecimento de jogo.

\subsection{Aprendizagem colaborativa apoiada por software}

A Internet contribuiu na popularização e no ensino do xadrez, e impactou nas estratégias adotadas no projeto das ferramentas de apoio ao ensino. A ênfase agora é na comunicação, convivência, e colaboração, entre aprendizes e instrutores, entre humanos e agentes virtuais [16].

A aprendizagem colaborativa tende a produzir resultados melhores do que a individual, pois nela a assimilação dos conceitos se concretiza por meio das interações do aluno com outros indivíduos, sejam eles aprendizes ou instrutores [17].

Uma das primeiras ferramentas com este enfoque foi o SHA-CHESS, que cria um tabuleiro de xadrez virtual 3D, e permiti compartilhá-lo com vários usuários simultaneamente. Através dela é possível enfrentar um jogador automático ou outros humanos, todos participando da mesma partida [18].

Depois em [19] foi apresentado o ambiente de ensino colaborativo ChessEdu. Este faz com que aprendizes pratiquem e aprendam xadrez jogando individualmente ou em grupos, enquanto um tutor acompanha-os, e interage com eles. Os usuários podem compartilhar comentários, acompanhar a realização de uma partida, e analisá-la adicionando anotações, ou alternativas de jogada.

Já no sistema virtual multimídia Chess Tutor, optou-se por priorizar as questões pedagógicas do ensino do jogo. Este prevê a interação entre um enxadrista experiente e seus alunos, ou entre os próprios estudantes. Para viabilizar isto, a ferramenta oferece cenários de colaboração que reproduzem fielmente comportamentos do ensino tradicional do jogo, realizados em escolas presenciais [20].
Netto em [21] propôs o AVAX (Ambiente Virtual para Aprendizagem de Xadrez), que trabalha com diferentes tipos de usuários (reais, clones virtuais, e agentes heterogêneos), todos se comunicando de forma integrada, em uma comunidade virtual de convivência. Nele é possível aos usuários de diversos níveis de experiência no xadrez, realizar atividades de aprendizagem como: jogar; participar de competições; analisar partidas; e treinar [21].

Martineschen em [22] descreve um ambiente de ensino onde o aluno formaliza o seu conhecimento heurístico de jogo, e a representação criada pode ser compartilhada com outros estudantes, e utilizada em jogadores automáticos como lógica de escolha de lances em uma partida artificial. Esta abordagem pretende estimular a alternância entre a colaboração e competição entre os aprendizes.

Como sequência a [22] foi desenvolvido em [1] a DHJOG e a ferramenta de autoria HeuChess, que permite a formalização deste tipo de conhecimento (Ver seção 1). Já em [23] incorporou-se na HeuChess novos módulos para o aperfeiçoamento das formalizações, um que permite a definição de situações de tabuleiro, e outro a avaliação de um caso específico por uma heurística.

Os trabalhos [1], [15], [22] e [23] fazem parte do PROTEX, e foram idealizados para serem disponibilizadas no mesmo ambiente virtual, o XadrezLivre (http://xadrezlivre.c3sl.ufpr.br). Que consiste em um servidor gratuito construído em software livre, que apoia a competição, o ensino e aprendizagem do jogo.

Concluímos que das ferramentas para aprendizagem de xadrez disponíveis, poucas propuseram novas abordagens. E as que a fizeram, a maioria preocupou-se mais com as questões técnicas, do que com o método de ensino, e acabaram por replicar os comportamentos feitos nos clubes presenciais de xadrez.

A formalização de conhecimento heurístico é proposta em raríssimos casos, e nestes sempre feita pelo especialista (i.e., instrutor). A exceção são os estudos [1], [2], [22] e [23], mas que devido a carências técnicas não tiveram a eficiência aferida à época. $\mathrm{O}$ que este trabalho veio a concretizar (Ver seção 4).

\section{Expansão dos conceitos e ferramen- tas computacionais}

Para que fosse possível verificar o impacto da formalização de conhecimento heurístico de jogo por aprendizes, foi necessário primeiramente expandir o conjunto de conceitos e ferramentais computacionais disponíveis com este enfoque.

As soluções que vêm de encontro a este objetivo foram apresentadas em [1]. São elas, a linguagem $D H J O G$ e 
a ferramenta de autoria HeuChess (Ver seção 2.4), e estas precisavam ser incrementadas a fim de suportar as seguintes funcionalidades: (i) gerenciamento de turmas e usuários; (ii) compartilhamento de representações heurísticas entre alunos; (iii) competição artificial entre heurísticas de xadrez; e (iv) registro das ações dos usuários.

\subsection{Linguagem de formalização heurística}

A $D H J O G$ foi criada com o intuito de permitir a formalização simplificada de conhecimento heurístico de jogo, o que facilita o estudo e compartilhamento destas representações entre aprendizes [1]. Ao utilizá-la é possível caracterizar mecanismos para:

- Identificar em qual estágio de uma partida o jogo se encontra, e quais heurísticas deverão ser analisadas neste contexto temporal.

- Definir a relação de importância entre os elementos do jogo, o valor absoluto e relativo das peças.

- Identificar contextos em uma determinada situação de partida, e especificar o quanto estes contribuem como vantagem ou desvantagem ao jogador.

- Especificar de que forma o cálculo heurístico será realizado.

Estes mecanismos permitem detalhar como um jogador planeja atuar durante uma partida, de acordo com as vantagens e desvantagens que ele identifica. $\mathrm{Na}$ seção 1 foram apresentados os tipos de vantagens de jogo suportados pela linguagem (i.e., material, espacial, e temporal), e a Tabela 1 exemplifica o seu uso.

No seu desenvolvimento foram adotados os seguintes conceitos: Regras de Produção; Máquina de Estados Finitos; Desenvolvimento Orientado a Funções; Primitivas Matemáticas; Níveis de Expressividade; e Apoio a Autoria e Colaboração. A especificação, projeto e uso inicial da linguagem estão detalhados em [1].

A primeira melhoria feita na linguagem foi incluir mecanismos que permitem identificar peças específicas de um jogador em um determinado contexto. Isto se deu com a adição de novas constantes, tais como: PEAO.MEU, PEAO.OPONENTE, TORRE.MINHA, etc. Como resultado, agora é possível utilizar os operadores de conjuntos (e.g., CONTEM, CONTIDO, IGUAL, e DIFERENTE), para comparar e testar a ocorrência de certos elementos.

No estudo de Bueno [23] foi realizada a avaliação heurística de situações de partidas através da DHJOG. Neste trabalho foi identificado que a proposta inicial da linguagem, de que uma regra heurística quando ativada alterava o valor heurístico de um ou mais tipos de peças, era limitada. Nesta proposição, todas as peças de um mesmo tipo seriam alteradas.
Nos testes práticos feitos com enxadristas foi constatado de que em cercos casos, era interessante valorar algumas peças de um tipo, e não todas. Por exemplo, um autor pode querer formalizar que "um peão atacando é mais importante que um sem ação". Desta forma, quando esta situação for identificada em uma partida, deve-se alterar o valor heurístico apenas dos peões que se enquadrem nesta circunstância.

Então para disponibilizar esta opção, o conceito de Heurística de Valor de Peça foi alterado. Agora este elemento é definido como:

- Uma regra de produção que quando sua condição for verdadeira, ela irá executar uma ou mais $A c ̧ \tilde{e} e s$ de Valoração de Peças.

- Uma Ação de Valor de Peça representa uma operação matemática no seguinte formato: \{conj. de peças\} op. aritmético valor numérico. O conjunto de peças alvo é encontrado a partir do uso de uma função pré-existente. $\mathrm{O}$ operador matemático é um dos elementares (e.g.,,,$+- \times, \div)$. $\mathrm{E}$ o valor numérico usado é uma constante real.

Com a criação de mecanismos visuais de detalhamento da avaliação heurística feita em uma situação de partida (Ver seção 3.2), fez-se necessário definir na DHJOG valores heurísticos simbólicos para os estados possíveis de uma partida. A Tabela 2 apresenta estes símbolos.

\begin{tabular}{c|c|c}
\hline Símbolo & Descrição & Significado \\
\hline$+\infty$ & $\begin{array}{c}\text { Infinito } \\
\text { positivo }\end{array}$ & Vitória minha \\
\hline 0 & Zero & $\begin{array}{c}\text { Situação neutra. } \\
\text { Ninguém possui vantagem } \\
\text { heurística. }\end{array}$ \\
\hline$-\infty+1$ & $\begin{array}{c}\text { Quase } \\
\text { negativito }\end{array}$ & Empate \\
\hline$-\infty$ & $\begin{array}{c}\text { Infinito } \\
\text { negativo }\end{array}$ & Vitória do oponente
\end{tabular}

Tabela 2 - Valores heurísticos simbólicos de resultados de partidas.

Neste trabalho houve a necessidade de refazer a ferramenta de criação de situações de partida (Ver seção 3.2). Com isto, surgiu à oportunidade de adaptar a linguagem para também representar este tipo de informação.

Uma Situação de Jogo possui um nome, uma descrição textual da aparente vantagem na partida, e a representação do momento atual em FEN (ForsythEdwards Notation). Este método de notação é utilizado para descrever completamente um determinando instante de uma partida de xadrez, com informações tais como: disposições das peças; quem irá jogar; movimentos especiais disponíveis (e.g., roque, en passant); e até a propensão atual para empate (regra dos 50 movimentos). 
Vale salientar que a vantagem aparente é a interpretação pessoal do autor da formalização sobre o contexto apresentado, e pode se mostrar equivocada.

\subsection{Ferramenta de autoria e competição}

A ferramenta HeuChess foi projetada e desenvolvida para facilitar o processo de autoria de conhecimento heurístico de xadrez, e para o estudo, compartilhamento e uso destas formalizações dentro de um processo de ensino e aprendizagem do jogo [1].

A autoria e uso deste tipo de conhecimento requer lidar com conceitos complexos (e.g., táticas de xadrez, mecanismos de formalização, funcionamento de jogadores automáticos), que demandam do indivíduo uma carga cognitiva inicial alta. A fim de amenizar este problema, na pesquisa realizada para o projeto da ferramenta foram estudadas e aplicadas diversas técnicas de representação de conhecimento, veremos a seguir as principais [1]:

- Uso de Múltiplas Representações Externas. O conhecimento é apresentado e manipulado pelo usuário utilizando-se de diferentes abordagens e representações. Onde ele opta pela que mais se adapte ao seu domínio atual da ferramenta e do conteúdo.

- Caixa Preta e Caixa de Vidro integrada. A autoria é realizada como um processo de modelagem e simulação, onde o usuário define modelos e regras que serão utilizadas pelo jogador automático durante uma partida artificial. A "caixa preta" consiste em permitir que simulações ocorram sem que o indivíduo conheça todos os mecanismos relacionados. Já o de "caixa de vidro" define que é possível analisar e alterar as características utilizadas no processo de simulação. Com a adoção combinada destas duas técnicas, o aluno consegue utilizar a aplicação deste o início dos estudos, e conforme consolida sua aprendizagem, acessa recursos mais avançados [24].

- Adaptação da Interface ao nível de conhecimento do autor. O projeto da DHJOG contempla diversos níveis de expressividade (Ver seção 3.1), e por isto a HeuChess permite ao usuário adaptar a interface gráfica de acordo com o seu nível de conhecimento da formalização de heurísticas. Isto simplifica o uso da aplicação, visto que mecanismos não dominados pelo aprendiz permanecem ocultos a ele.

- Geração Automática de Codificação. O processo de formalização de conhecimento heurístico de jogo através da DHJOG resulta em vários elementos codificados (e.g., regiões, etapas, heurísticas, funções, etc.). A ferramenta torna transparente ao usuário a geração destas estruturas.
Podemos elencar também: o recurso de Arrastar e soltar; a utilização de Facilitadores de Tarefas; a definição visual de regiões de tabuleiro (com uso de ferramentas de desenho); o agrupamento e classificação de funcionalidades similares; e a visualização da relação entre as Etapas (que representam momentos temporais de uma partida) através do uso de Diagrama de Estados. Todos visando facilitar o uso da solução pelos aprendizes iniciantes [1].

Para viabilizar o estudo empírico sobre o uso da formalização de conhecimento heurístico (Ver seção 4), uma das primeiras ações técnicas foi prover a ferramenta de mecanismos para gerenciamento de instituições, turmas, e usuários. Foi então criado um conjunto de papéis (perfis) para os atores do ambiente, e de acordo com as atribuições definidas a cada um, as novas funcionalidades são liberadas para acesso. Agora existem as figuras de: (i) aluno; (ii) coordenador de turma; (iii) coordenador de instituição, e (iv) administrador do sistema. Sendo que uma pessoa pode ter papéis diferentes em contextos diferentes. Por exemplo, um indivíduo pode ser aluno da turma $X$, e coordenador da turma $Y$.

Um usuário pode formalizar dois tipos de conteúdos: Situação de Jogo; e Conjunto Heurístico. E estes itens criados são armazenados em um repositório virtual. Cada pessoa pode fazer parte de uma ou mais turmas. E para cada grupo que ela pertença é possível listar seus colegas e coordenadores, e de acordo com as permissões de compartilhamento pode-se acessar os repositórios dos colegas. A Figura 2 exibe a tela onde esta ação ocorre.

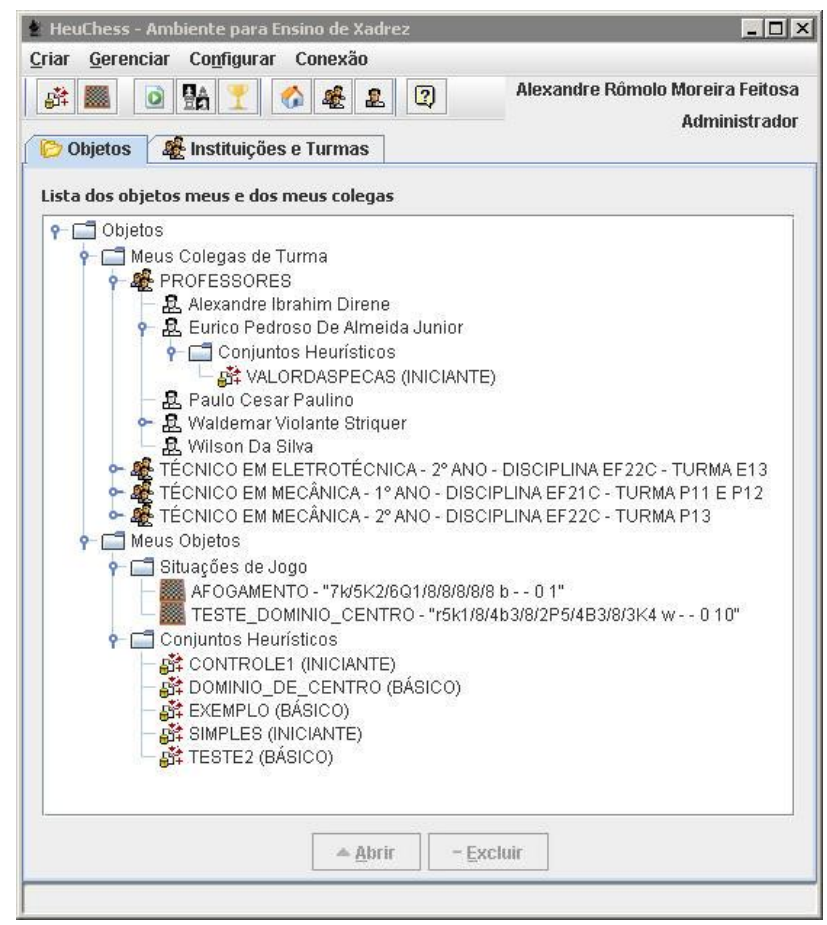

Figura 2 - Tela de visualização de objetos próprios e dos colegas. 
Dentre as diversas atribuições de um coordenador de turma, uma importante de se destacar é a de definir a política de compartilhamento do material formalizado por aprendizes da mesma turma. Pois através desta ação, ele pode fixar momentos de alternância entre a colaboração e competição entre os estudantes. Pode-se especificar se o membro de uma turma pode: acessar; usar (através da avaliação ou competição heurística); anotar; ou alterar um objeto de outro colega. Esta definição pode ser modificada a qualquer momento, e não faz referência ao uso dos próprios objetos por um usuário.

Uma etapa importante para o aprendizado enxadrístico é o de especificação de situações de partida. Nesta ação o aprendiz descreve detalhadamente um determinando instante de um jogo. O trabalho de Bueno [23] incluiu uma primeira versão de um módulo para esta atividade na HeuChess. Porém esta foi projetada para ser usada por enxadristas especialistas (i.e., tutores), na construção de material pedagógico para aprendizes.

Nesta pesquisa expandimos este conceito para permitir que esta formalização possa ser feita também por estudantes, e para que as situações de jogo criadas possam ser compartilhadas com outros usuários do sistema. Para tal, a $D H J O G$ foi expandida para permitir esta tarefa (Ver seção 3.1), e a interface gráfica deste módulo foi refeita. A Figura 3 apresenta esta nova ferramenta.

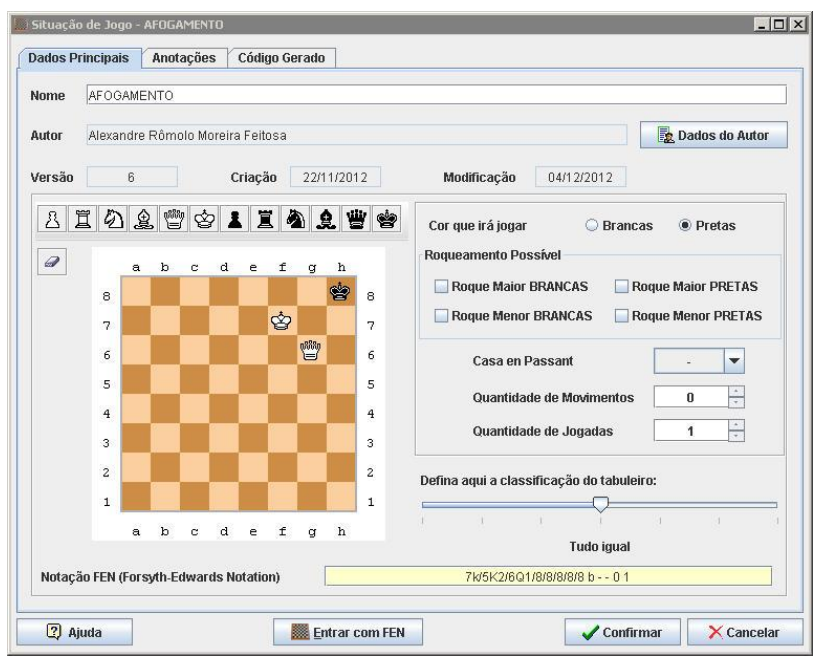

Figura 3 - Tela Situação de Jogo - Aba principal.

A formalização de conhecimento heurístico para ser usado por um jogador automático compreende a criação de diversos itens (e.g., heurísticas, regiões, etapas, etc.), que estarão encapsulados em um objeto chamado na DHJOG de Conjunto Heurístico [1]. Com as expansões feitas nesta linguagem (Ver seção 3.1), e com a inclusão de novas funcionalidades de avaliação heurística (que estão na sequência), alguns módulos de formalização da ferramenta de autoria também precisaram ser adaptados.
Primeiramente, quando um usuário especifica uma região de tabuleiro para utilizá-la na construção de uma regra heurística, ele deve fazê-lo independente da cor de peças. Pois o Conjunto Heurístico por ele criado poderá jogar com as brancas ou com as pretas. Durante os testes feitos constatou-se que este conceito de simetria, que foi discutido em [1], permanecia confuso aos indivíduos. Então para evitar erros, incluiu-se na interface de formalização de regiões uma opção que permite ver em tempo real a área simétrica da que esta sendo especificada.

Com a modificação da especificação das heurísticas de valoração de peças na $D H J O G$ (Ver seção 3.1), a interface de autoria destes elementos precisou ser atualizada. Foi então desenvolvido um facilitador de tarefa para a criação e edição de Ações de Valoração de Peças, e na tela de edição de heurísticas foi adicionado o gerenciamento destes novos itens. A Figura 4 apresenta o momento de formalização de uma destas heurísticas.

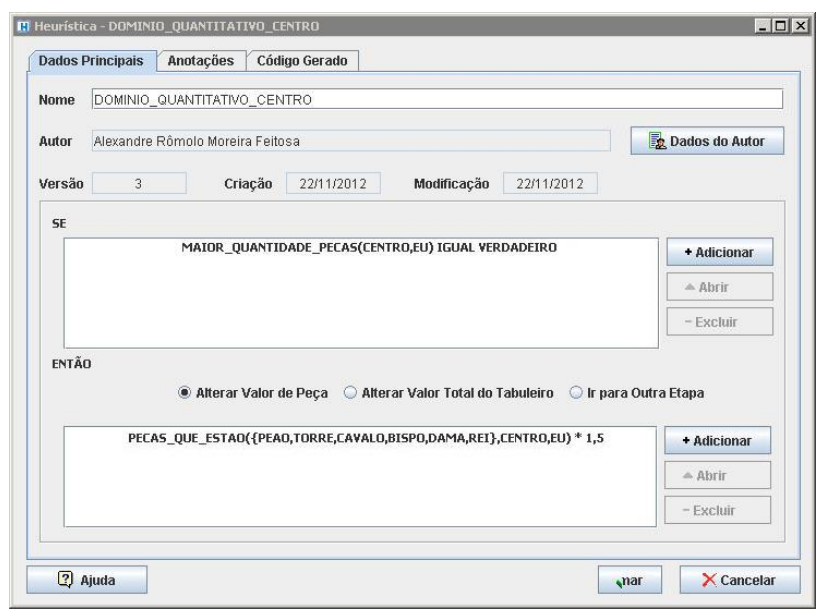

Figura 4 - Edição de uma Heurística de Valor de Peças.

Um Conjunto Heurístico nada mais é do que uma função de avaliação utilizada por um jogador automático para valorar os possíveis tabuleiros resultantes, das admissíveis próximas jogadas, e de acordo com os valores encontrados, o programa escolherá o movimento que leve ao tabuleiro de menor vantagem ao oponente, e de maior vantagem para o jogador (Ver seção 2.2).

$\mathrm{O}$ uso de um conjunto para avaliar apenas um tabuleiro, fora do contexto de uma partida artificial, contribui para a compreensão pelo aprendiz dos conceitos envolvidos, e propicia o refinamento deste elemento durante a sua formalização, já que permite testar sua atuação em determinadas situações de jogo. Esta funcionalidade foi inicialmente feita em [23] direcionada a usuários experientes, porém com a inclusão neste trabalho de novos conceitos na DHJOG (Ver seção 3.1), este módulo precisou ser refeito. E neste novo projeto, optou-se por uma interface mais intuitiva para uso também por iniciantes. 
Um dos objetivos deste trabalho foi permitir a um aprendiz formalizar conhecimento heurístico de xadrez, e validar esta especificação através da competição artificial entre sua criação e a de outros estudantes. Foi desenvolvida então uma ferramenta que permite ao usuário criar uma partida artificial entre dois Conjuntos Heurísticos. Nela é possível especificar: o tabuleiro inicial (i.e., Situação de Jogo); a cor; a profundidade de busca de cada jogador; e o modo de execução do confronto (Automático ou Passo a Passo).

No modo Automático, os dois jogadores artificiais vão escolhendo as jogadas de forma alternada, sem aguardar qualquer interação humana. Já no Passo a Passo um jogador automático realiza o movimento, e a interface apresenta informações que permitem entender como foi feita a escolha daquela ação, e para passar a vez de jogar para o outro programa jogador, o usuário deve ativar um dos botões de navegação. A Figura 5 apresenta esta tela.

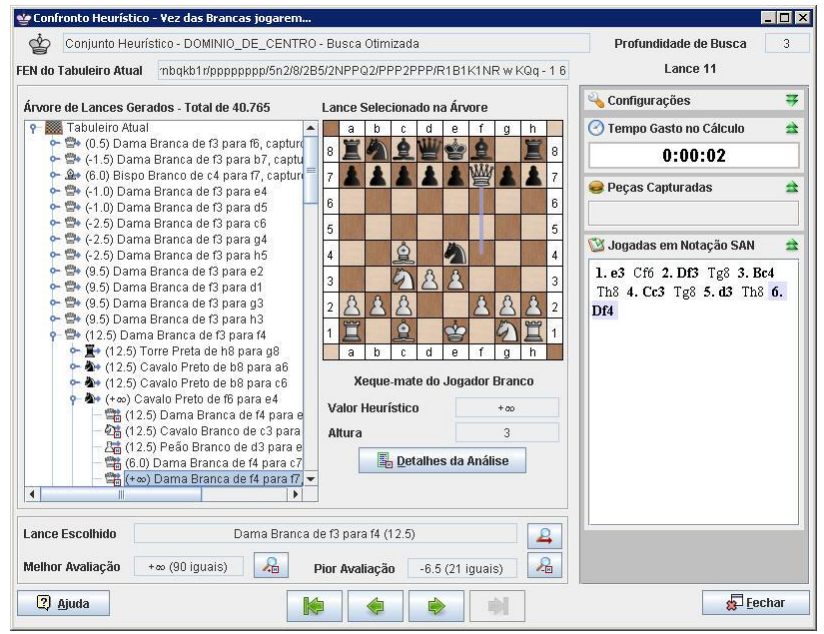

Figura 5 - Confronto heurístico no modo de execução passo a passo.

O modo Passo a Passo fornece funcionalidades similares as de depuração (debug) encontradas em ambientes de programação, e através delas é possível: (i) estudar toda a árvore de lances gerados; (ii) verificar o valor heurístico de cada nó da árvore; (iii) ler a descrição da avaliação heurística dos tabuleiros finais (ou nós folhas) da árvore; e (iv) ver a quantidade de avaliações iguais a pior e a melhor realizada, e localizar uma de cada.

Com a viabilização do confronto heurístico foi possível desenvolver um módulo que permite a um usuário criar campeonatos entre Conjuntos Heurísticos, que incluam suas formalizações, e dependendo das permissões de compartilhamento, também a dos colegas de turma. O torneio segue o formato Round Robin (todos contra todos ou pontos corridos). Neste sistema: vence quem conseguir a maior pontuação; o número de partidas é igual para todos; a classificação final é considerada justa, visto que todos se enfrentam; perder uma partida não é tão desastroso; porém gera-se um número elevado de confrontos.

Como no xadrez existe certa vantagem em jogar com as brancas (pois iniciam a partida), cada heurística enfrenta outra duas vezes, cada vez com uma cor de peça. A tela de execução de campeonato é apresentada na Figura 6.

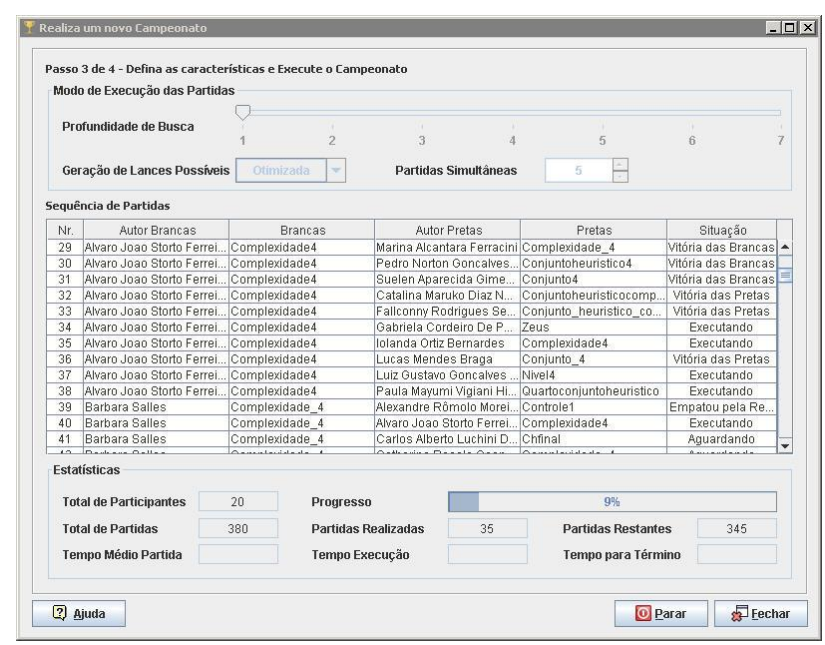

Figura 6 - Executando partidas artificiais do campeonato.

A cada partida é atribuído uma pontuação pela vitória, empate, ou derrota para cada conjunto, sendo estes valores e a profundidade de busca definidos pelo usuário. Ao final somam-se todos os pontos, e gera-se a classificação. Caso existam competidores com a mesma pontuação, o primeiro critério de desempate é a quantidade de vitorias, e depois o total de empates, e se mesmo assim persistir a igualdade, ambos recebem a mesma posição.

Estas novas funcionalidades foram criadas através de vários ciclos de tarefas (e.g., análise, projeto, programação, testes, e refinamento), de forma iterativa e incremental, e adotando métodos ágeis de desenvolvimento.

\section{Estudo empírico}

Com a expansão do ferramental, foi possível conduzir um estudo empírico para analisar o impacto do estimulo a formalização de conhecimento heurístico de jogo por aprendizes, e da alternância entre colaboração e competição entre estes estudantes, dentro de um processo real de ensino e aprendizagem de xadrez.

\subsection{Metodologia}

A metodologia utilizada na realização do estudo contém diversas atividades, que estão agrupadas em 5 etapas: (i) planejamento; (ii) preparação; (iii) aplicação; e (iv) diagnóstico. Sendo esta última dividida em competição artificial e análise dos resultados encontrados. Algumas destas fases ocorreram linearmente, já outras em ciclos. 
O perfil dos usuários alvo foi de adolescentes, enxadristas iniciantes, com experiência em informática. E consistia de três turmas matutinas do ensino médio integrado da UTFPR (Universidade Tecnológica Federal do Paraná), do campus Cornélio Procópio. Uma turma do $2^{\circ}$ ano de Técnico em Eletrotécnica, e duas do Técnico em Mecânica (uma do $1^{\circ}$ e outra do $2^{\circ}$ ano). Nestes cursos, na disciplina de Educação Física, é ensinado xadrez por um bimestre em duas horas-aula por semana.

As ferramentas de formalização de conhecimento heurístico foram incorporadas no ferramental pedagógico utilizado pelos instrutores, como atividade extraclasse de fixação de conteúdo através da realização de exercícios práticos. E estas atividades corresponderam a $20 \%$ da nota bimestral de cada estudante na disciplina envolvida.

Os métodos científicos utilizados para a coleta dos dados relacionados às tarefas feitas pelos alunos foram:

- Estudos exploratório-descritivos combinados. Nesta abordagem podem ser realizadas análises empíricas e teóricas, e os métodos de amostragem são maleáveis, e possibilita encontrar tanto descrições qualitativas quanto quantitativas [25].

- O método clínico de Piaget. Este consiste em conversar livremente com o indivíduo, sem um roteiro e perguntas fixas, conservando desta forma as vantagens de uma fala adaptada a cada sujeito. $\mathrm{O}$ que garante o máximo de consciência ao entrevistado, e possibilitando a este formular e descrever suas próprias atitudes mentais [26].

Foi preparado junto a cada instrutor um plano de ensino e de atividades para sua turma. Neste documento foram indicados os conteúdos de xadrez abordados, e em quais momentos aconteceriam: (i) a formalização de heurística pelos alunos; (ii) a competição entre as representações criadas; e (iii) a alternância entre as fases de competição e colaboração.

Os exercícios propostos foram encadeados de forma evolutiva. Onde cada passo abrange um escopo limitado do nível de expressividade da linguagem $D H J O G$, e de conceitos táticos do xadrez. E o passo seguinte inclui o que foi tratado anteriormente, e incorpora novas funcionalidades e características a serem aplicadas.

\subsection{Aplicação}

No primeiro dia foi aplicado um questionário para diagnóstico dos alunos em relação a contextos relacionados ao estudo, tais como: conhecimento prático de informática; disponibilidade de acesso à internet (para a realização dos exercícios no contraturno); domínio atual sobre o xadrez; objetivos pessoais em relação à aprendizagem do jogo; dentre outros.
No total participaram 87 estudantes, sendo 64,4\% de homens e a idade média de 16,8 anos. Onde cada turma possuía cerca de 30 indivíduos.

Sobre o xadrez: 75,9\% aprenderam na escola; a idade média do início da aprendizagem foi de 10,7 anos; somente $28,7 \%$ participaram de competições; a média semanal de prática era de apenas 1,35 horas (80,8 minutos); $42,5 \%$ consideram-se com nenhum ou pouco conhecimento; $42,5 \%$ com domínio regular; só $14,9 \%$ achavam que possuíam uma boa ou ótima experiência; a maioria $(70,1 \%)$ queria apreender o suficiente para se tornar um bom jogador com o intuito de praticar casualmente; 5,7\% gostariam de aprofundar os estudos a nível profissional; $21,8 \%$ queriam compreender o básico; e 2,3\% (dois alunos) nem queriam aprender (mas era obrigatório visto que constava de disciplina da grade curricular).

De posse destes dados foi possível adaptar a aplicação das atividades propostas ao perfil de cada turma, e ao final, utilizar destas informações prévias para a identificação de relações, dependências, e influências nos resultados alcançados.

Os alunos tiveram duas semanas para desenvolveram os exercícios propostos, e podemos classificar as tarefas passadas nas seguintes categorias:

(i) Formalização de conhecimento heurístico, sendo Situações de Jogo e Conjuntos Heurísticos.

(ii) Criação de material de estudo. Onde cada formalização criada deveria conter textos explicativos sobre os conceitos, táticas, e abordagens tratadas, para auxiliar os outros alunos na compreensão.

(iii) Estudo dos materiais criados pelos colegas.

(iv) Competição artificial. Cada aprendiz deveria criar partidas automáticas entre os seus Conjuntos Heurísticos, e entre os dele contra os dos colegas.

As tarefas das categorias (ii) e (iii) contribuíram para a colaboração entre os estudantes, já as da categoria (iv) estimularam a concorrência e aperfeiçoamento entre eles.

Durante a realização do estudo prático foi disponibilizado aos aprendizes períodos para atendimento presencial, onde estes poderiam receber treinamento e sanar as dúvidas. Estas atividades foram marcadas no período da tarde (contraturno), e nelas ocorreram as entrevistas individuais sobre os contextos pertinentes, seguindo o método clínico de Piaget.

Sobre estes atendimentos constatou-se que: apenas dezesseis aprendizes $(18,4 \%)$ participaram; a média de comparecimento foi de apenas 1,6 encontros; que as duas turmas de Mecânica tiveram participação mínima de $4,85 \%$; e que a turma de Eletrotécnica teve participação de metade dos seus integrantes, o que correspondeu a $81,3 \%$ do total de presentes. 
Ao término das duas semanas ocorreu a aplicação de um questionário final de diagnóstico, e a tabulação de todas as atividades desenvolvidas pelos aprendizes.

Sobre a entrega das tarefas foi visto que: (i) a criação de Situações de Jogo, por ser mais simples, a maioria fez; (ii) a criação do Conjunto Heurístico de nível 4, que seria utilizada nos campeonatos das turmas (Ver seção 4.3), apenas $17,6 \%$ dos alunos a fizeram; (iii) a turma do $1^{\circ}$ ano de Mecânica foi a que menos cumpriu as atividades (33\%); e (iv) por sua vez, o $2^{\circ}$ ano de Eletrotécnica foi a que mais entregou os exercícios (70,1\%).

A turma do $2^{\circ}$ ano de Mecânica teve participação geral de $68,8 \%$, ou seja, próxima da Eletrotécnica. No entanto, apenas 10,3\% dos alunos desta turma de Mecânica entregaram um Conjunto Heurístico de nível 4, contra $42,3 \%$ da turma de Eletrotécnica. Vemos que esta última superou em muito a primeira nas atividades de colaboração, competição, e nas de esclarecimentos de dúvidas (aonde apenas 3,4\% de alunos da primeira turma vieram).

O uso da HeuChess também foi avaliado pelos alunos, sendo que: $69,2 \%$ acreditam que a adoção da ferramenta ajudou na compreensão de conceitos do jogo; 10,3\% disseram que ela contribui um pouco, mas não totalmente; e 20,5\% afirmaram que ela não auxiliou.

Procuramos entender os motivos que levaram 16 estudantes a responder não a questão, e constatamos que $43,8 \%$ justificaram sua resposta ao fato de já dominarem os conteúdos cobrados nos exercícios, e assim, a ferramenta não os auxiliou. Os demais ainda não compreendiam os assuntos, porém destes $88,9 \%$ não se predispuseram a vir em nenhum dos quatro atendimentos. $\mathrm{O}$ único aluno destes que veio compareceu a apenas um encontro, e foi um dos dois indivíduos que no questionário inicial afirmou não possuir interesse em aprender xadrez.

Cabe salientar que na HeuChess não havia nenhum material para estudo dos conteúdos de xadrez. A ferramenta serviu apenas para a resolução de exercícios práticos de formalização de conhecimento, e para a competição artificial. Sendo que estas tarefas foram passadas aos aprendizes para a fixação dos temas abordados anteriormente pelos instrutores. Isto valoriza ainda mais a grande quantidade que afirmou que o uso deste ferramental contribuiu na compreensão dos conteúdos tratados.

\subsection{Campeonatos artificiais}

Com o objetivo de aferir a eficácia das formalizações de conhecimentos táticos de xadrez criadas pelos alunos, foram realizados torneios entre os Conjuntos Heurísticos de nível 4. Devido ao fato de que somente os elementos deste tipo possuem transições entre etapas, o que permite definir heurísticas diferentes para momentos distintos de uma partida (i.e., abertura, meio de jogo, e final).

Foi utilizado o módulo de execução de campeonatos criado neste trabalho, que gerencia torneios Round Robin (i.e., todos contra todos). E como no xadrez existe uma pequena vantagem para quem joga com as brancas, pois realizam o primeiro movimento, dois conjuntos heurísticos se enfrentam duas vezes, alternando as cores usadas (Ver seção 3.2). Desta maneira, a quantidade de confrontos a serem realizados na competição é calculada através da fórmula $n \times(n-1)$, onde $n$ corresponde ao total de competidores.

Para gerar a classificação final foi usado o seguinte critério: uma vitória vale 3 pontos; um empate vale 1; e uma derrota não vale nenhum ponto. $\mathrm{O}$ desempate segue os critérios padrões da ferramenta (Ver seção 3.2).

Além dos conjuntos dos alunos, também foi incluído no torneio um mecanismo de controle de eficiência mínima da formalização do conhecimento heurístico, que consistia em um jogador automático que escolhia de forma aleatória o lance a ser realizado. Assim conseguimos verificar se os conjuntos criados são pelo menos melhores do que o acaso na escolha das jogadas.

Cada competição teve três ciclos de confrontos, com diferentes alturas de árvore de busca. Deste modo foi possível verificar o desempenho dos conjuntos em profundidades de análises distintas.

Era esperado realizar um campeonato para cada turma de alunos. Infelizmente na turma do $1^{\circ}$ ano de Mecânica nenhum aluno conseguiu entregar um Conjunto Heuristico de nível 4, e na turma do $2^{\circ}$ ano de Mecânica apenas 3 alunos o fizeram, o que resultou em um escopo muito limitado.

Apenas na turma do $2^{\circ}$ ano de Eletrotécnica a criação de conjuntos de nível 4 foi satisfatória, sendo de 42,3\% dos estudantes (Ver seção 4.2).

O resultado final da competição realizada entre os membros desta turma está devidamente detalhado na Tabela 3, e nela constatamos que:

- Os alunos 68, 81, 64, e 74 permaneceram sempre no topo da classificação.

- Os alunos 71, 66, e 73 ficaram sempre no final da classificação.

- Os alunos 79, 72, 69, e 70 oscilaram muito na classificação entre os vários ciclos.

- Todos superaram o mecanismo de escolha aleatória de jogadas.

Identifica-se claramente na Tabela 3 que alguns conjuntos foram bem superiores aos outros, durante os vários ciclos da competição. Isto evidencia que alguns aprendizes foram mais eficientes nesta tarefa de formalização. 


\begin{tabular}{|c|c|c|c|c|c|}
\hline $\begin{array}{c}\text { Identificação no } \\
\text { estudo }\end{array}$ & Altura 1 & Altura 2 & \multicolumn{2}{|c|}{ Altura 3 } & \multicolumn{2}{|c|}{ Análise após 3 ciclos } \\
\cline { 2 - 6 } & Classificação & Classificação & Classificação & $\begin{array}{c}\text { Soma } \\
\text { dos } \\
\text { pontos }\end{array}$ & $\begin{array}{c}\text { Média da } \\
\text { classificação }\end{array}$ \\
\hline Aluno 68 & $1^{\circ}$ & $1^{\circ}$ & $1^{\circ}$ & 155 & 1,0 \\
\hline Aluno 81 & $2^{\circ}$ & $3^{\circ}$ & $2 \circ$ & 139 & 2,3 \\
\hline Aluno 64 & $6^{\circ}$ & $5^{\circ}$ & $3^{\circ}$ & 116 & 4,7 \\
\hline Aluno 74 & $5^{\circ}$ & $4^{\circ}$ & $5^{\circ}$ & 115 & 4,7 \\
\hline Aluno 79 & $10^{\circ}$ & $6^{\circ}$ & $3^{\circ}$ & 102 & 6,3 \\
\hline Aluno 72 & $11^{\circ}$ & $2^{\circ}$ & $8^{\circ}$ & 101 & 7,0 \\
\hline Aluno 69 & $4^{\circ}$ & $9^{\circ}$ & $6^{\circ}$ & 94 & 6,3 \\
\hline Aluno 70 & $3^{\circ}$ & $7^{\circ}$ & $9 \circ$ & 86 & 6,3 \\
\hline Aluno 71 & $8^{\circ}$ & $11^{\circ}$ & $7 \circ$ & 69 & 8,7 \\
\hline Aluno 66 & $6^{\circ}$ & $8^{\circ}$ & $10^{\circ}$ & 64 & 8,0 \\
\hline Aluno 73 & $9^{\circ}$ & $10^{\circ}$ & $11^{\circ}$ & 45 & 10,0 \\
\hline Escolha Aleatória & $12^{\circ}$ & $12^{\circ}$ & $12^{\circ}$ & 17 & 12,0 \\
\hline
\end{tabular}

Tabela 3 - Resultado do campeonato da turma do $2^{\circ}$ ano de Eletrotécnica.

\subsection{Análise sobre os resultados encontrados}

$\mathrm{Na}$ realização do estudo prático identificamos como principais contratempos ocorridos a baixa participação dos alunos: nos eventos extraclasse de atendimento de dúvidas; e na criação do Conjunto Heurístico de nível 4. Isto obviamente considerando-se o total de alunos envolvidos, das três turmas trabalhadas.

Apenas $18,4 \%$ dos aprendizes vieram pelo menos uma vez nas atividades dedicadas a atendimento, e a maioria dos que vieram pertencem a um único grupo, que foi a turma do $2^{\circ}$ ano de Eletrotécnica. Porém se considerarmos apenas ela, a taxa de participação também é aquém do esperado, e ficou em apenas $50,0 \%$ dos integrantes.

Esta circunstância nitidamente prejudicou os estudantes no desenvolvimento das tarefas mais complexas passadas a eles, que são as de criação de Conjuntos Heurísticos de nível 2,3 , e 4 , onde respectivamente, a participação geral ficou em $36,4 \%, 39,4 \%$ e 17,6\%.

Os fatores que levaram os aprendizes a não vir nestes encontros são de ordem subjetiva, contudo podemos especular a respeito. Entendemos que algumas questões podem ter desestimulado eles, tais como:

- Os encontros terem ocorrido no contraturno, visto que a grade matutina de disciplinas estava lotada.

- A não obrigatoriedade da participação, e nenhuma relação entre a presença nesta atividade com a nota ou total de faltas finais da disciplina.

- A relação baixa da avaliação do estudo prático dentro da nota bimestral da disciplina, pois ela correspondia a apenas $20 \%$ da nota final. Assim sendo, a não realização das tarefas propostas não impedia o aluno de alcançar pelos menos à média necessária para aprovação (que era de 7,0).
Outro item que não estimulou certos aprendizes a concluir o exercício final de criação do Conjunto Heuristico de nível 4, é o fato de que do total de tarefas propostas, ela representava apenas $6 \%$ da avaliação (foram passadas a cada turma 16 atividades valendo 2,0). Ou seja, realizar esta ação representava 0,12 décimos da nota final bimestral da disciplina. Só a concluiu o indivíduo realmente motivado a apreender xadrez, a cooperar com o estudo, ou a alcançar a nota final máxima.

Mesmo com a baixa conclusão dos exercícios finais, entendemos que a grande participação dos alunos nas outras atividades colaborou para que alcançássemos os objetivos propostos neste estudo.

Desde o início, trabalhamos com a possibilidade de que por razões diversas, grupos de indivíduos poderiam ter taxas de participação diferentes. E como forma de minimizar este risco, optou-se em aplicar o estudo empírico a três turmas simultaneamente.

Das três turmas trabalhadas, duas alcançaram médias gerais de participação muito boas. $\mathrm{O} 2^{\circ}$ ano de Mecânica com $68,8 \%$, e o $2^{\circ}$ ano de Eletrotécnica com $70,1 \%$. E considerando apenas o último exercício, a turma de Eletrotécnica obteve $42,3 \%$ de sucesso. O que já permitiu a execução do campeonato artificial com uma amostragem suficiente para análise.

Com os dados coletados dos membros do grupo da Eletrotécnica na fase de diagnóstico inicial, e durante o desenvolvimento das atividades propostas (Ver seção 4.2), traçamos as relações entre algumas destas informações e os resultados obtidos no torneio artificial. Isto para identificar razões que contribuíram ou prejudicaram certos estudantes na formalização de conhecimento heurístico de xadrez, que alcançasse um bom desempenho nos confrontos automáticos. A Tabela 4 traz os dados que permitem esta análise. 


\begin{tabular}{|c|c|c|c|c|c|c|c|}
\hline $\begin{array}{c}\text { Classificação } \\
\text { final }\end{array}$ & $\begin{array}{c}\text { Identificação } \\
\text { no Estudo }\end{array}$ & $\begin{array}{c}\text { Coeficiente } \\
\text { geral } \\
\text { acadêmico }\end{array}$ & $\begin{array}{c}\text { Desempenho } \\
\text { anterior } \\
\text { em } \\
\text { Matemática }\end{array}$ & $\begin{array}{c}\text { Quantidade } \\
\text { de } \\
\text { componentes } \\
\text { do Conjunto } \\
\text { Heurístico }\end{array}$ & $\begin{array}{c}\text { Quantidade } \\
\text { de acessos } \\
\text { de } \\
\text { conjuntos } \\
\text { nível } 3 \text { e } \\
4 \text { dos } \\
\text { colegas }\end{array}$ & $\begin{array}{l}\text { Quantidade } \\
\text { de parti- } \\
\text { das com } \\
\text { conjuntos } \\
\text { de Nível } 3 \\
\text { e } 4 \text { dos } \\
\text { colegas }\end{array}$ & $\begin{array}{l}\text { Qual é sua } \\
\text { experiência } \\
\text { em jogar } \\
\text { xadrez }\end{array}$ \\
\hline $1^{\circ}$ & Aluno 68 & 0,909 & 9,6 & 10 & 26 & 1 & Boa \\
\hline $2^{\circ}$ & Aluno 81 & 0,898 & 9,1 & 12 & 104 & 4 & Boa \\
\hline 30 & Aluno 64 & 0,860 & 8,1 & 18 & 26 & 3 & Regular \\
\hline $4^{\circ}$ & Aluno 74 & 0,878 & 9,8 & 13 & 117 & 15 & Regular \\
\hline $5^{\circ}$ & Aluno 79 & 0,858 & 8,5 & 12 & 26 & 7 & Pouca \\
\hline $6^{\circ}$ & Aluno 72 & 0,855 & 8,4 & 20 & 52 & 10 & Pouca \\
\hline 70 & Aluno 69 & 0,832 & 7,8 & 12 & 91 & 3 & Pouca \\
\hline $8^{\circ}$ & Aluno 70 & 0,948 & 9,6 & 15 & 0 & 6 & Boa \\
\hline $9 \circ$ & Aluno 71 & 0,740 & 7,0 & 15 & 91 & 0 & ótima \\
\hline $10^{\circ}$ & Aluno 66 & 0,816 & 7,3 & 20 & 0 & 3 & Pouca \\
\hline $11^{\circ}$ & Aluno 73 & 0,944 & 10,0 & 21 & 0 & 0 & Regular \\
\hline
\end{tabular}

Tabela 4 - Relação das características dos competidores da turma do $2^{\circ}$ ano de Eletrotécnica.

Nas informações da Tabela 4 identificamos que:

- Existe uma relação direta entre o desempenho geral acadêmico, o conhecimento prévio de matemática, e a experiência em xadrez que o aluno julga ter, com a performance da heurística formalizada por ele na competição. Os primeiros classificados possuem os melhores valores para estes atributos. As exceções são os alunos 70, 71, e 73.

- Os alunos 70 e 73 têm alto coeficiente acadêmico e anterior em matemática, e dizem ter experiência em xadrez respectivamente boa e regular, mas mesmo assim ficaram no final da classificação.

- O aluno 71 apesar de ter o menor coeficiente geral e de matemática, é o que diz ter o maior domínio em xadrez, porém ficou no final da competição.

- Os alunos 70,71 e 73 não acessaram ou não criaram partidas com os conjuntos de nível 3 ou 4 dos colegas.

- A quantidade de componentes muda na classificação sem formar uma tendência. Primeiro está o com menos (10), e em último o com mais (21), e entre eles varia-se. O que nos leva a concluir que o importante para o desempenho não é a quantidade, e sim a qualidade do conhecimento formalizado.

- Nas últimas posições estão os alunos que não acessaram, ou não criaram partidas automáticas utilizando os conjuntos de nível 3 ou 4 dos colegas.

A partir deste exame inferimos o quão importante é a colaboração e competição entre os estudantes, durante o processo de aprendizagem e formalização de conhecimento heurístico de xadrez, para alcançar uma perfor- mance ótima em competições artificiais.

Ter bom coeficiente acadêmico e anterior de matemática, e experiência no jogo é recomendável, mas não suficientes para garantir a eficiência das heurísticas criadas.

A competição artificial não era a única tarefa proposta, era a mais complexa, e até podemos entendê-la como atividade fim. Entretanto, para que esta fosse realizada o indivíduo deveria completar exercícios anteriores, que o iriam capacitando na formalização de conhecimento, e nos conteúdos tratados de xadrez. Até que este alcançasse a maturidade cognitiva para a construção de um conjunto de nível 4. Este processo evolutivo foi previsto e incluído nos planos de atividades das turmas (Ver seção 4.1).

Dito isto, percebemos que mesmo os alunos que não concluíram a ultima tarefa, mas fizeram a maior parte das anteriores, estes conseguiram se beneficiar da abordagem de aprendizagem proposta neste estudo. Pelos menos dos benefícios associados à formalização e colaboração entre aprendizes, e a maioria deles se enquadrou neste perfil. E aqueles que executaram partidas automáticas somente com os conjuntos mais simples, estes também se beneficiaram, mesmo que parcialmente, da simulação artificial como instrumento para entender certos conceitos do xadrez, e do funcionamento dos programas jogadores.

Por exemplo, $62,1 \%$ do $2^{\circ}$ ano de Mecânica, e 88,5\% do $2^{\circ}$ ano de Eletrotécnica usaram um Conjunto Heuristico para avaliar uma situação de partida, e $58,6 \%$ da primeira, e $80,8 \%$ da segunda criaram partidas automáticas. Estes números explicam o fato de que $69,2 \%$ dos alunos afirmaram que o uso da ferramenta de formalização de conhecimento heurístico de jogo os auxiliou a compreender melhor conceitos de xadrez. Uma taxa bem superior a dos indivíduos que entregaram o conjunto de nível 4 , que 
foi de apenas $17,6 \%$ (Ver seção 4.2).

E para $10,3 \%$ a ferramenta ajudou pouco na compreensão dos conteúdos. Somando-se este número aos discutido no parágrafo anterior, chegamos a $79,3 \%$ de alunos que obtiveram algum benefício, mesmo que pequeno para uma parcela, na aprendizagem de xadrez decorrente do uso do ferramental e do método proposto nesta pesquisa.

Apesar de esta ser a primeira análise sobre esta abordagem, e a mesmo ter sido feito de forma empírica para uma quantidade limitada de indivíduos, os resultados encontrados são evidentes. Podemos constatar que a hipótese levantada por esta pesquisa é valida (Ver seção 1). A de que em um processo de ensino e aprendizagem de xadrez, o uso da formalização de conhecimento heurístico de jogo por aprendizes contribui para uma melhor compreensão dos conceitos tratados. E que a realização de tarefas de colaboração e competição deriva em formalizações mais eficientes em torneios artificiais.

Obviamente estas constatações não esgotam o tema, e sim possibilitam que novas questões científicas sejam postas, e novos usos para o ferramental sejam testados.

\section{Conclusão}

Primeiramente revisou-se a bibliografia e os trabalhos relacionados a esta pesquisa (Ver seção 2), e ao final constatou-se a ausência de ferramentas computacionais que permitissem a formalização de conhecimento heurístico de jogo pelos estudantes, e que as especificações criadas fossem usadas em confrontos artificiais. Nenhuma solução com este enfoque estava apta a ser utilizada em um processo real de ensino. O que impedia a aferição do impacto da adoção desta abordagem.

Devido a isto, foi feita a expansão necessária nestes conceitos e ferramentas. Dando continuidade a pesquisas anteriores ocorreram melhorias na linguagem DHJOG e no programa de autoria HeuChess, onde foi incluído entre vários módulos, um para permitir a competição artificial entre as heurísticas criadas pelos alunos (Ver seção 3).

De posse deste novo arcabouço, finalmente foi possível conduzir um estudo empírico sobre o uso desta prática no ensino e aprendizagem de jogos. Adotou-se a formalização de heurísticas por aprendizes e a colaboração e competição entre eles, como instrumento pedagógico de fixação de conteúdos de xadrez, previamente ensinados por instrutores (Ver seção 4).

E verificou-se que este método auxiliou $69,2 \%$ dos indivíduos a melhor compreender os conceitos de jogo trabalhados, e que a colaboração e competição entre os mesmos são de suma importância para a criação de representações heurísticas eficazes nos confrontos artificiais
(Ver seção 4.4).

Desta maneira, conseguiu-se aferir a hipótese proposta e concluir que esta é válida. O que contribui com a solução do problema identificado no ensino tradicional de xadrez, da ausência de mecanismos para a formalização de conhecimento heurístico por aprendizes (Ver seção 1).

Entendemos que as metas alcançadas por este trabalho permitem inferir os seguintes benefícios e possibilidades: (i) melhorar e disponibilizar um conjunto público de softwares para apoio ao ensino de xadrez, centrado na formalização heurística; (ii) refinar a precisão da validação do aprendizado de xadrez; (iii) promover o uso do xadrez como instrumento de ensino e de prática de outros conhecimentos do currículo escolar básico (e.g., Matemática, Comunicação, etc.), visto que a formalização heurística utiliza princípios lógico-matemáticos, e a colaboração entre os alunos desenvolve aspectos de sociabilidade, convivência, e de expressão; e (iv) facilitar a compreensão e uso dos conceitos de Inteligência Artificial por pessoas leigas, tais como o que é heurística e como a mesma é processada por um jogador automático.

Por fim, elencamos como possíveis temas para trabalhos futuros: (i) expandir a DHJOG para incluir a formalização de estratégias de jogo de longa duração; (ii) permitir que uma heurística desista da partida, ou force um empate; (iii) criar ferramentas que usem conceitos da DHJOG para o ensino e aprendizagem de outros jogos (e.g., dama, gamão, etc.); e (iv) diminuir o conhecimento cognitivo necessário à realização das tarefas de formalização heurística através da incorporação de novas técnicas de projetos de interface, de representações externas de conhecimento, e de agentes inteligentes que auxiliem os usuários na realização das ações típicas.

\section{Referências}

[1] A. Feitosa, A. Direne, F. Silva, L. Bona, A. Guedes, M. Castilho, M. Sunye, L. Garcia: Definição formal de táticas de xadrez por meio da autoria incremental de conceitos heurísticos. Anais do XVIII Simpósio Brasileiro de Informática na Educação (SBIE), páginas 244253, São Paulo, SP, 2007. 
[2] A. Direne, L. Bona, F. Silva, G. dos Santos, A. Guedes, M. Castilho, M. Sunyé, C. Hartmann, P. de Andrade Neto, S. de Mello, J. Sunyé Neto, W. Silva. Conceitos e ferramentas de apoio ao ensino de xadrez nas escolas brasileiras. Em Anais do XXIV Congresso da Sociedade Brasileira de Computação: WIE - Workshop sobre Informática na Escola, Salvador, Brasil, R. Macedo, Ed., SBC, páginas 816-825, 2004.

[3] A. Cleveland. The psychology of chess and of learning to play it. The American Journal of Psychology, v. 3, 269-308, 1907.

[4] A. de Groot. Thought and choice in chess, 1946. 2. ed. New York: Mouton Publishers, 1978.

[5] J. V. Neumann, O. Morgenstern. Theory of games and economic behavior, 1944. 6. ed. New Jersey: Princeton University Press, 1990.

[6] A. M. Lesgold, H. Rubinson, P. F. R. Glasser, D. Klopfer, Y. Wang. Expertise in a complex skill: Diagnosing x-ray pictures. In Chi, M., Glasser, R., and Farr, M., editors, The Nature of Expertise. Lawrence Erlbaum, 1989.

[7] M. Bilalic, A. Kiesel, C. Pohl, M. Erb, W. Grodd. It Takes Two-Skilled Recognition of Objects Engages Lateral Areas in Both Hemispheres. Revista PLoS ONE, 24/01/2011.

[8] M. Campbell, A. J Hoane Jr., F-H Hsu. Deep Blue. Artificial Intelligence, 134 (1), 57-83, 2002.

[9] A. Junghanns, J. Schaeffer, M. Brockington, Y. Björnsson, T. Marsland. Diminishing Returns for Additional Search in Chess. Advances in Computer Chess 8, 1997.

[10] C. Donninger, U. Lorenz. Innovative OpeningBook Handling. Advances in Computer Games. Lecture Notes in Computer Science, v. 4250, 1-10, 2006.

[11] S. Lopez. Chess Software Buying Guide. Publicado em: 2005. Disponível em: www.chesscentral.com/Chess Software Buying Guide a/141.htm. Acessado em: 20/10/2011.

[12] H. S. Nwana. Intelligent tutoring systems: an overview. Artificial Intelligence Review, 4(4): 251-277, Dezembro 1990.

[13] D. Gadwal, J. E. Greer, G. I. McCalla. UMRAO: A chess endgame tutor. Proceedings of the 12th international joint conference on Artificial intelligence. Publisher: Morgan Kaufmann Publishers Inc., páginas 1081-1086, 1991.
[14] S. G. Lazzeri, R. Heller. ICONCHESS: an Interactive CONsultant for CHESS middlegames. Proceedings of the international conference on Learning sciences - ICLS, 1996.

[15] H. Schafer, A. Direne. Conceitos e ferramentas para apoiar o ensino de Xadrez através de computadores. Anais do XI Simpósio Brasileiro de Informática na Educação (SBIE), Maceió. Editora da UFAL, páginas 97-104, 2000.

[16] K. Pereira, V. R. Ulbricht, T. Vanzin; L. F. J. Maia. A internet e a dimensão criativa no jogo de xadrez. In: Conferência IADIS 359. IberoAmericana $W W W /$ Internet 2008, Lisboa. Atas da Conferência. IADIS Press, páginas 121-128, 2008.

[17] L. S. Vygotsky. Mind in Society - The Development of Higher Psychological Process. Cambridge MA: Havard University Press, 1978.

[18] V. Anupam, C. L BAJAJ. Collaborative Multimedia Game Environments. Computer Science Technical Reports. 01/12/1993.

[19] M. A. Mora, R. Moriyón. Guided collaborative chess tutoring through game history analysis. $2^{\circ}$ Simpósio Internacional de Informática Educativa. Puertollano, 2000.

[20] F. J. García, M. N. Moreno, J. R. GarcíaBermejo. Collaborative multimedia environment for chess teaching. Int. J. Computer Applications in Technology, Vol. 29, No. 1, 2007.

[21] J. F. M. Netto, O. L. Tavares, C. S. Menezes. Um Ambiente Virtual para Aprendizagem de xadrez. Workshop - Jogos Digitais na Educação, Anais do XVI SBIE, Juiz de Fora, MG, 2005.

[22] D. Martineschen, A. Direne, L. Bona, F. Silva, M. Castilho, A. Guedes, M. Sunyé. Alternância entre competição e colaboração para promover o aprendizado por meio de heurísticas de jogos. Anais do WIE2006-Workshop sobre Informática na Escola, páginas 1-10, Campo Grande, 2006.

[23] L. Bueno, A. Direne, A. Guedes, F. Silva, L. Bona, L. Garcia, M. Castilho, M. Sunye. Visualização de táticas para apoiar a aquisição de habilidades em jogos educacionais. Anais do XXVIII Congresso da Sociedade Brasileira de Computação - SBC, Workshop sobre Informática na Escola, v. 1, páginas 380-389. 2008. 
[24] T. Murray, L. Winship, R. Bellin, M. Cornell, Toward Glass Box Educational Simulations: Reifying Models for Inspection and Design, Workshop External representations in AIED, San Antonio, Texas, 2001.

[25] M. A. Marconi, E. M. Lakatos. Técnicas de pesquisa. 4. ed. São Paulo: Atlas, 1999.

[26] T. S. Valente. Pesquisa em psicologia genética: o método clínico. Campinas, 1997. 